\title{
LUTO Y FORMA EN LA POESÍA DE BAUDELAIRE
}

\author{
Silvio Mattoni \\ Universidad Nacional de Córdoba \\ silviomattoni@yahoo.com.ar
}

Resumen: El tema del luto es un motivo que aparece con cierta frecuencia en la poesía y la prosa de Baudelaire. El fondo sobre el cual se destacan los trajes negros y los vestidos de luto es la ciudad, su movimiento de oleaje de las multitudes. Pero también en el sentimiento del duelo, en el espacio íntimo de los recuerdos que acuden al llamado rítmico del verso, se encuentra el significado y la función de la pérdida como eje a cuyo alrededor se organiza la poesía, el signo de su inutilidad que detiene, en la escritura, el paso veloz de los habitantes urbanos.

Palabras clave: Baudelaire, Poesía Francesa, Modernidad, Duelo.

\begin{abstract}
The topic of the mourning is a motive that appears with certain frequency in Baudelaire's poetry and prose. The backdrop on which are outlined the black suits and the dresses of mourning is the city, his movement of surge of the multitudes. But also in the feeling of the duel, in the intimate space of the memories that come to the call rhythmic of the verse, it finds the meaning and the function of the waste as axis to whose around is organized the poetry, the sign of his uselessness that stops, in the writing, the fast step of the urban inhabitants.
\end{abstract}

Keywords: Baudelaire, French Poetry, Modernity, Mourning. 
Es bien conocida la descripción vestimentaria que realizara Baudelaire en el "Salón de 1846" del héroe de la modernidad, más precisamente de la vida cotidiana en el tiempo de la aceleración técnica del tiempo. Frente a los persistentes talleres de pintura que satisfacen el gusto de un público desorientado con ropajes antiguos, se pregunta entonces si el traje negro y la levita no tienen su belleza y su encanto propios, originales: "¿No es acaso el traje necesario de nuestra época, que sufre y lleva sobre sus hombros negros y flacos el símbolo de un duelo perpetuo?". Y él mismo responde que esas ropas negras "no solamente tienen su belleza política, que es la expresión de la igualdad universal, sino también su belleza poética, que es la expresión del alma pública -un inmenso desfile de enterradores, enterradores políticos, enterradores enamorados, enterradores burgueses. Todos celebramos algún entierro" (Baudelaire, 1868, p. 195). El heroísmo se incrementa en razón de la imposibilidad de su éxito. La conciencia de Sísifo, que sabe que su esfuerzo reiterado no podrá prevalecer sobre la inercia general, pareciera más ejemplar en el presente que los antiguos modelos heroicos, teñidos de abnegación, temeridad o voluntad de sacrificio. De allí surge una conocida estrategia estética, menos obstinada que el mero combate contra lo invencible, que Baudelaire llamó "dandysmo". Y sin embargo, más allá de tal distanciamiento irónico, fuera de la potencia apenas sugerida de un artista que se representa a sí mismo como un Hércules sin empleo, ¿cuál sería el objeto del duelo que se atestigua de manera general y que incita a la diferenciación perpetua de pliegues y de signos en la superficie del negro obligatorio? ¿Acaso hay un objeto? Todos 
celebramos algún entierro, aunque no sería el mismo para todos, pero también podríamos decir que no se trata de varios para cada uno.

Quisiera destacar ahora un par de términos que le dan al pasaje un matiz burlón, una especie de lenguaje popular y despectivo a la vez, que acompaña la crítica de la pintura arcaizante en el detallado informe de Baudelaire. En primer lugar, designa la ropa moderna como "la pelure", que es una forma coloquial de nombrar todo tipo de vestimenta, pero que en realidad deriva de su sentido propio: "cáscara", más precisamente la cáscara que se descarta al pelar una fruta. En principio, antes de que el dandy corra ansiosamente a plegar sus volados, el uniforme de la ropa moderna es signo de la indigencia universal. Pero alguien así, vestido de cáscaras, parte animada de un residuo que camina entre la multitud, evidentemente ha sufrido y carga con el peso traumático que debería ser, necesariamente, el mensaje de su manera de aparecer en público. Sin embargo, el luto, el signo del traje negro, deja de significar debido a su misma universalidad. Alguien de luto transmite una muerte precisa, durante un período de tiempo, a una comunidad que lo diferencia. Pero si todos celebran un idéntico luto, no es posible saber cuál sería su objeto. El luto exterior, ahora incomunicable, se convierte en duelo, abusando un poco de la doble terminología castellana para una sola palabra francesa.

No obstante, este andar desolado, heroísmo del sujeto cualquiera que se viste como todos, tiende más a la comicidad que a lo trágico. Cada uno sería antes bien un payaso 
sepulturero que juega con restos, a escondidas, de vuelta en su casa, más que un artista de alma excepcional que se sienta en alguna tumba a escribir o a dibujar. Este matiz payasesco del héroe moderno, que sólo sería tal en todo caso por su conciencia de sí, por saber que no tiene meta, que su tarea no tiene fin, se advierte en la otra palabra burlona que usa repetidamente Baudelaire para referirse a los "enterradores", políticos, enamorados y burgueses. Se trata de "croque-morts". Es una manera también vulgar de referirse a los sepultureros, de origen dieciochesco. Términos más llanos serían fossoyeur, que viene del verbo que significa "cavar", o bien enfouisseur, que proviene de otro que quiere decir "sepultar", pero también "esconder" o "hundir". Por último, un término culterano, menos usado, sería "nécrophore", derivado del griego, o sea "el que transporta muertos". Pero, ¿de dónde viene "croque-morts"? Del verbo "croquer", en un sentido secundario de "hacer desaparecer". Estos funebreros, que son todos los habitantes de una ciudad vestidos a la moda, se afanan en hacer que los muertos desaparezcan. Sin embargo, hay otros sentidos primarios del mismo verbo, que explicarían además el apuro y la crispación, la machaqueante ansiedad de cada héroe sin nombre; croquer significa "masticar, mordisquear". Cada cual entonces mastica su propia pérdida, se remuerde con un duelo que no puede comunicar, aunque no por una deficiencia en la capacidad de transmitir algo, sino porque no hay sitio, ya no hay lugar donde eso se pueda decir. ¿Qué harán entonces nuestros héroes, esos masticamuertos? Se entregarán a las tareas sugeridas por otros sentidos del verbo croquer: por un lado, "dibujar, describir, bosquejar" - de allí deriva la palabra 
"croquis"-, es decir, perseguir lo que se pierde a cada paso, la diferencia en la uniformidad de la ciudad, ser artistas, registrar en lo que aparece la resurrección imaginaria de aquello que los vistió de luto. $\mathrm{Y}$ por otro lado, croquer también significa: "dilapidar, malgastar, derrochar", tirar lo que se cree tener, perder el tiempo y la vida, entregarse al más virtuoso de los goces, el sacrificio interminable de un gasto simbólico. Si sólo supieran lo que hacen, que coincide con lo que son, cualquiera de esos croque-morts habría de ser lo que todavía llamamos un artista, o al menos Baudelaire aún podía tener derecho a celebrar este nombre.

Pero el luto no es solamente un signo de lo que se guarda por medio del dibujo o del poema, tampoco un mero gesto de lo que se derrocha en el tiempo perdido, con los dientes apretados de una ansiedad diferida en los momentos de embriaguez. Es además la señal de un duelo que se recuerda, que vuelve siempre, o que incluso se remonta a lo inmemorial. El luto representa hasta el duelo por la poesía que se introduce en el tiempo pasado, como un género vencido. Baudelaire sabe bien, como lo indicara Benjamin, que la poesía en verso está en dificultades con la época, que ha emprendido su interminable camino hacia el eclipse. En la ciudad entonces, entre las ruinas de las demoliciones que darán lugar a nuevos edificios, el que escribe versos piensa en términos de duelo. "Andrómaca, pienso en vos", comienza el famoso poema LXXXIX de Las flores del mal, el más alegórico de sus "Cuadros parisinos" (Baudelaire, 1975, p, 85). Y ahora no nos interesa tanto el cisne que lo protagoniza, grotesco resurgimiento de una figura ampulosa del poeta, como esa introspección histórica que 
parte en dos la duración de un paseo melancólico. La Andrómaca del principio, cuyo río, cuya ciudad derrotada han alimentado un gesto, no por reivindicatorio menos conscientemente inútil, de escribir en cuartetos alejandrinos rimados, se refleja en los marineros, tal vez náufragos, de la isla remota en el final del poema. Andrómaca, de luto, aunque viuda sin derecho a vestirse como tal, es cualquier exiliado, es una negra tísica que patina en el barro de un París medieval que está desapareciendo. Pero el poeta, que deja de mirar la escena de la obra en construcción, se aferra a los nombres del mito, a la esperanza de una literatura. Como la negra enferma en la ciudad, que busca cocoteros ausentes, extraviada, "tras la muralla inmensa de la niebla". Como cualquiera que perdió lo que no se recupera, nunca. ¿Quiénes son todos ellos? ¿Qué multiplican los huérfanos, los cautivos y los vencidos? Se alimentan de lágrimas, los amamanta el dolor, dice el poeta con su brutalidad habitual. Son pobres masticadores de pérdidas que no tienen siquiera un nombre, una palabra griega como "Andrómaca", apta para los orgullosos versos racinianos.

Pero volvamos al último cuarteto:

Así en el bosque donde mi espíritu se exilia / suena un viejo Recuerdo a pleno soplo de corno; / pienso en los olvidados marinos de una isla, / en vencidos, en presos... y en muchos otros más" (1975, p. 87).

La ciudad en obras, que demuele las huellas de una memoria biográfica, trae consigo, por su misma negatividad, esa suerte de bosque interno, un duelo que se exilia en el poema porque ya no caben lutos, aunque sí ropajes oscuros, en la prosa 
cotidiana. Y ahí sopla un recuerdo antiguo, es y no es Andrómaca, esa lectura de infancia, es todo lo irrecuperable que hace llorar porque nunca se volverá a ver, pero es algo que de todos modos sopla, en su mismo movimiento de ausentarse, es apenas aire de unas alas ridículas y fuera de lugar. Frente a los bloques, los andamios, los barrios viejos y los nuevos bulevares, un soplo vacío parece retornar, volver livianas esas memorias personales, la condena singular de ser el que es, que parecían más pesadas que piedras. El recuerdo es único, no se refiere a nada, pero en él caben todos los otros, cada cual con su dosis incomunicable de pérdida, cada cual en su silencio enfermizo. El recuerdo no es la fábula del cisne escapado de un circo y apresado en la construcción que avanza, sino que es apenas rítmico, es el poema mismo, su sentimentalismo y su simetría de una cesura al medio de cada verso, que se espera como quien esperara acordarse de una sonrisa de juventud que ahora habría quedado reducida a un nombre.

Ahora bien, el poema es un registro que se esboza al regresar de una caminata, un paseo o un trámite que de repente parece haber propiciado un acontecimiento. Febrilmente, se anotan unos versos, el ritmo y las breves estrofas con sus retornos sonoros van llevando a lo que sigue, parecieran hacer posible ese registro. $\mathrm{Y}$ como es sabido, el acontecimiento es esencialmente un instante inscripto en la duración de una vida, un punto en un entramado de líneas que no se sabe dónde empiezan ni dónde terminan. El acontecimiento es entonces una idea de la muerte, ya que implica la duración del cuerpo, su desgaste, su decadencia irreversible. Pero por esto mismo 
también sería la posibilidad de una redención, o al menos una justificación de esa vida que muere, que dura y soporta. El punto, inextenso, no puede registrarse, pero el registro de todos modos se esboza, con rapidez, con el ritmo que escande la memoria para cortar en su tela confusa el agujero nítido de un recuerdo. A veces no llega siquiera a representarse como una vuelta del pasado, sino que acaba de suceder y se lo marca antes de que sea llevado por las olas de todo lo que pasa. El recuerdo está de luto, quizás, por su propio destino de pérdida.

Otra resurrección de la viuda prototípica, Andrómaca, que nunca abandonará su luto -en contraste con la madre de Baudelaire, viuda demasiado rápida en aceptar el olvido, según la memoria rencorosa del poeta-, aparece en el soneto dedicado a una mujer que pasa. El signo anómalo del duelo hará que un cuerpo que simplemente pasaba procure ahora ser fijado en la forma idealizada que llamamos "soneto", con sus dos cuartetos que presentan al tema, el personaje, sus ropas y gestos, y luego los dos tercetos con las conclusiones sentimentales, alegóricas y vitales. La mujer pasó, delgada y alta, vestida de un luto completo. El deseo, que todo lo divide, se apodera de la mirada que distingue en el negro total un ruedo, un borde festoneado, cuyas sacudidas hacen adivinable la pierna de estatua, la firmeza altiva de una juventud que ha quedado vacante. Como Andrómaca, es un objeto que ostenta el gesto de una refutación de su condición. Su vestimenta indica que no está disponible, pero también lo contrario. La ambivalencia de sentimientos hace posible pensar que si el instante se detuviera y el poeta pudiese conocer a la viuda, tal vez se encontraría en la posición del sustituto, el que hace 
olvidar al muerto. La sed ante lo que parece deseable y al mismo tiempo se sustrae crispa la vista fija de un transeúnte para nada despreocupado, puesto que lee la duración mortal en cada cosa, en cada grupo de gente, en cada edificio y en cada rostro. No es un paseante más, un dandy que se niega a rebajarse en la forma de una obra, sino un "extravagante", un trabajador de lo inútil. Su sed entonces toma el agua del instante en los ojos de la viuda ágil, que levanta su ruedo para caminar más rápido, y saborea lo posible, aunque no exista, es decir, el acontecimiento irreversible, el "cielo lívido donde germina el huracán" (Baudelaire, 1975, p. 92). Cielo suave que fascina, porque la pupila detenida un segundo en el acto de ser mirada no puede apartarse sino después, apresada, captada e impactada; y huracán que se desataría si el instante se multiplicara. No olvidemos que el "flechazo", este giro bélico con el que designamos el amor a primera vista -aunque en el caso del duelo de Baudelaire, que combate con lo que huye, se trate de un amor a última vista-, se dice en francés el "golpe de rayo", le coup de foudre, un deseo instantáneo que anuncia la tormenta amorosa. Pero aquí el relámpago no trae nada más, todo queda oscuro. La noche incitará a escribir una forma secular de versos que no dejen pasar del todo, aunque de hecho pase, la aparición de la mujer vestida de negro. "Belleza fugitiva" -concluye filosóficamente el que ha vuelto a su pieza de escritura-, "cuya mirada me hizo renacer de repente" (1975, p. 93). Pero la sed no se sacia, la visión no se repetirá, tal vez, sino en la eternidad. Y justamente, lo que Baudelaire llama "eternidad" es la muerte, la mitología literaria, sin cuerpo, sin duración de fondo para que se destaquen los destellos 
relampagueantes de algo que pasa. Eso está muy lejos, demasiado tarde, gloria póstuma que apenas dice: "esto se vivió una vez y ya nunca más”. Así termina el último terceto: "Porque ignoro adonde fuiste, no sabés adonde voy, / ah, a vos te hubiese amado y lo sabías" (93). La paseante, que no está paseando precisamente, que se apura en el acto de pasar, pero mira y se hace ver, viste un luto completo por la retracción de lo posible que indica toda muerte. El tiempo huye, pero a su vez en cada uno nada se mueve, lo único que podría redimir los momentos anodinos de la vida sería el instante de la visión estética y extática, aun cuando la crispación de esa disciplina de captación del instante pueda resultar agotadora. La mujer no es una estatua y el tiempo también la hará su presa, se la llevará, la volverá una viejita de otra escena, la arrastrará fuera de la vista como la marea de la multitud que la trajo y la retiró de golpe. Y en esta retracción se sustrae la necesidad del desgaste, el deterioro del cuerpo, lo real en su manifestación cruda, o cruel, si se quiere.

Muchos poemas antes en Las flores del mal, que también indicaría, según la filología, muchos años antes de la cumbre del libro que son los "Cuadros parisinos", en el poema XXIX, hay una alegoría barroca, casi literal en su cita del pasado, sobre la descomposición de la carne. En "Una carroña", precisamente, el poeta le describe a su amante algo que vieron juntos: un cadáver de animal pudriéndose. Las estrofas son complicadas, cuartetas en una especie de pie quebrado, donde dos versos racinianos son cortados por dos octosílabos (eneasílabos para nosotros) y riman entre sí los versos de igual medida. No menos compleja, detallada, proliferante resulta la 
pintura, como se decía entonces, de la mencionada carroña. Recién después de treinta y siete versos descriptivos, sobre el momento pasado que compartieron el poeta y su interlocutora, y que se recupera en el barroquismo del detalle, con un colorido que no deja de ser idealizante, se anuncia el memento mori y se le dice a la muchacha, a su belleza: "Y sin embargo serás como esta basura, / esta infección horrible, / estrella de mis ojos, sol de mi naturaleza, / vos, mi ángel y mi pasión" (1975, p. 32). Pero aun entonces el poeta habrá guardado, según concluye, "la forma y la esencia divina / de mis amores descompuestos" (p. 32). El amor entonces, con ese aire conceptual que nos recuerda tantas piezas similares, vence o trasciende a la muerte. Pero hay un detalle que afirma en cambio la presencia de lo pasajero, más que su reducción al gesto artístico de "petrarquizar el horror", para usar una expresión crítica de un contemporáneo de Baudelaire. Otro francés de antaño, el comentarista de la edición de La Pléiade, menciona esa diferencia: mientras que la advertencia macabra del barroco procuraba hacer que la dama cediera sus favores, su belleza efímera, nuestro cosechador de "flores del mal" ya obtuvo y sigue obteniendo el cuerpo de su interlocutora, protagonista además de otros poemas y otras encrucijadas de su vida y su escritura ${ }^{1}$. ¿A qué viene entonces lo macabro? ¿Por qué recordar el deterioro del cuerpo cuando lo que está presente es su plenitud y su duración constante? Para

\footnotetext{
${ }^{1}$ Claude Pichois, editor de las Oenvres en La Pléaide, realiza este comentario y cita una referencia actualizada: Cynthia Grant Tucker, "Petrarchisant sur l'horrible': A Renaissance Tradition and Baudelaire's Grotesque", The French Review, abril de 1975 (en Baudelaire, 1975: 889-890).
} 
intensificar el momento, para hacer que su goce se acerque, aun en su repetición, al acontecimiento definitivo y definitorio.

Y éste sería la pintura, el poema, donde lo que se pierde no se recupera, donde se traza un sustituto de algo que nunca existió, porque para ello habría que haber experimentado el presente ya como recuerdo, o sea: habría que vivir alegóricamente. El poema o el cuadro persisten, por supuesto, pero lo que deseaban está en otra parte. Hay que volver a intensificar los colores con lo que se pone negro, volver a mirar lo que se descompone, tal como el luto, siempre en oferta para la transgresión, intensifica el placer, cuya posibilidad tiene una potencia ilimitada, tal como el duelo, la reminiscencia de una pérdida que no se conoce, intensifica el gesto de escribir. En mitad de la descripción, se explica el carácter aporético, imposible de la captación plástica del presente: "Las formas se borraban y no eran más que un sueño, / un lento esbozo por venir, / olvidado en la tela y que el artista termina / sólo por medio del recuerdo" (Baudelaire, 1975: 32). Y sin embargo, aun el esbozo señala la invitación de la intensidad, la plenificación potencial del aquí y ahora.

Como en otro poema, "Las joyas", proscripto por la censura y por lo tanto destacado entre las "Piezas condenadas", que indica de manera afirmativa, en otra descripción de pretensiones plásticas, eso que llamamos la intensificación del momento de goce. La muy querida en el poema está desnuda, se había desnudado y sólo había dejado sobre su cuerpo unas joyas, más bien collares y otros accesorios que tintineaban, puesto que ella se dedicaba a una especie de baile, preliminar, 
antes de acostarse para que el poeta la amara y la mirase desde abajo, "como el mar / que subía hacia ella como a su acantilado" (Baudelaire, 1975, p. 158). Luego la subjetividad del que escribe es sacudida en su peñasco de cristal, donde se había sentado a solas, por "su brazo y su pierna, y su muslo y sus flancos relucientes". Pero la mirada se concentra, la alteración es una agudeza sensible, ya que las partes del cuerpo deseado pasaban ante los ojos, según la descripción, "clarividentes y serenos". Los comentarios de este poema lo suelen relacionar con algún cuadro de Delacroix e incluso podemos pensar en alguna odalisca de Ingres, con cinturones, collares y brazaletes sobre la piel. Pero no se trata de una écfrasis, de un retorno del viejo consejo que recomendaba $u t$ pictura poesis, sino de un relato en pretérito, un instante que se vuelve a esbozar con la técnica del recuerdo, donde se enlaza de nuevo la palabra con el sexo que sólo designan las palabrotas, las llamadas malas palabras, esas infinitamente ingenuas flores del mal.

El erotismo decimonónico envejece rápidamente, y este tipo de poemas puede ser mirado, como dice el mismo Baudelaire, desde un balcón donde las épocas, vestidas con ropa pasada de moda, escucharan una invocación antigua a la "madre de los recuerdos, amante de las amantes". El recuerdo del goce no restablece más que un imaginario placer de escribir, donde lo que se apaga rima con el aliento agitado que de a poco se normaliza. Pero el color ámbar de una piel, inundado de tintes sanguíneos por la crepitación del hogar, no se absorbe en la alegoría del goce pasajero, de la belleza efímera. Fue una justificación del instante, del presente que el poema mira, 
revisa, esboza. Es la justificación misma de la existencia del poema en la intensificación de una vida, y más todavía porque lo vivo es alguien más, alguien que misteriosamente se dedica a la hipnotización estética del que mira. Sin embargo, a pesar de la intención de volver a ver, justamente en la ausencia de otros sentidos, en la falta de palabras del acto narrado, el cuerpo sigue siendo una representación, estatua o pintura. Lo sensible se consume como una serie de poses, y algo pétreo se insinúa en los miembros pulidos, en los tonos de cada parte corporal. Debajo del luto no debería haber una estatua enjoyada, sino una voz en el presente del cuerpo, el recuerdo de un nombre, el origen de las palabras que hacen posibles las fantasías de la memoria. Sólo lo que se pierde no es igual para todos, no es una imagen, es como una lengua que ya nadie habla pero que todavía puede escribirse. Los libros cambian, pero el deseo de literatura es inamovible como los recuerdos y apunta, en su misma forma a veces inescrutable, en su ritmo más que en su relato, hacia la modulación de una voz, alianza siempre inconclusa entre el nombre y el cuerpo.

En una lengua perdida, que podría ser toda la poesía como género ritmado e inconsumible, acaso se pueda salir de la división fetichista del cuerpo en sus partes, y convertir el nombre en la unidad que anima una incierta presencia; así se sustituye la vista, su goce fálico, por el repiqueteo táctil que constata un llamado.

En el singular poema latino "Franciscae meae laudes", el número LX del libro, que Baudelaire insistió en repetir en dos ediciones de su poesía para marcar, tal vez, que no era un 
vacuo ejercicio literario, en el sentido escolar en que se hacían versos latinos en su época, se escucharía entonces, según la nota del poeta, "la lengua de la última decadencia latina", donde "el solecismo y el barbarismo parecen mostrar las negligencias forzadas de una pasión que se olvida y se burla de las reglas. Las palabras, tomadas en una acepción nueva, revelan la torpeza encantadora del bárbaro del norte arrodillado ante la belleza romana. El mismo retruécano, cuando atraviesa esos pedantescos tartamudeos, ¿no realiza acaso la gracia salvaje y barroca de la infancia?" (1975, p. 940). Vale decir, Baudelaire se pregunta por la intensidad que reduce la forma al rango de un señalamiento, pero también esa reducción concentra la forma, y el deseo de lo que se puede perder juega con las palabras que nunca se tienen del todo. "Novis te cantabo chordis, / O novelletum quod ludis / In solitudine cordis" (1975, p. 61). O sea: "Te cantaré con cuerdas nuevas, / oh pimpollito que juegas / en la soledad de mi corazón". ¿Qué resuena en nosotros, todavía, en ese bajo latín? ¿Hay algo además en su cursilería, en su laudatio de una modista, en la franca ironía de un nombre? Ella en realidad es no sólo el motivo del poema, sino su agente; es el sujeto del canto en latín. Esa "femina delicata" tiene el poder de absolver los pecados de existir, la separación de la singularidad. En esa lengua perdida, se sumergen el poeta y la causa de las rimas en octosílabos latinos, dando el paso histórico de los pies hechos de sílabas largas y breves al conteo de todas ellas y a sus ecos. Allí la poesía desaparecida insiste en su retorno. "Piscina plena virtutis, / Fons aeterna juventutis, / Labris vocem redde mutis!" (1975, p. 62). Que sería: "Piscina llena de virtud, / 
fuente de eterna juventud, / devuélvele la voz a mis labios mudos". La voz del poeta vuelve en el gusto, en lo que saborea, en el "aqua tincta seraphica" que anota esos versos de afirmación, en el "pan salado" que acompaña el final del poema, la comida suave, cuando se exclama: "Divinum vinum, Francisca!", vino divino de la unicidad que recibe, si acaso, la traducción arcaica de su propio nombre. Y esta inmersión en el latín contiene también un vestigio de infancia, la sonoridad extraña de una canción, la gracia salvaje y barroca, la equívoca pronunciación que se mueve en el paso de los idiomas.

Sólo un momento, el cuerpo, y después pasa. Pasan las lenguas, aunque la escritura las fije, como pasan las modas a pesar del ojo crispado del artista que las entiende y las aprecia en su heroísmo luctuoso. La poesía está de negro porque los goces se van y tienen que irse, destellos en la noche, tragos de vino, reverberaciones de una piel. Están muertos los amigos de la poesía, que escribieron antes y escribirán después, como si estuviesen a siglos del presente. El presente, mientras tanto, en el ritmo dislocado, se aferra a su íntima fugacidad. Yves Bonnefoy dijo que los ripios, las licencias o errores métricos en los alejandrinos de Baudelaire, sus cesuras violentas o violentadas, eran signos de la conciencia de su propio cuerpo, de la conciencia de estar, paso a paso, muriéndose: síncopas como latidos acelerados o calmados.

Sobre el soneto "Recogimiento", incorporado en la edición de 1868, escrito pues en los últimos años, Valéry decía que el segundo cuarteto contenía versos de "una indiscutible debilidad", pero que "los primeros y los últimos versos de ese 
poema poseen tanta magia que la parte media no deja percibir su ineptitud y fácilmente se considera nula o inexistente" (en Baudelaire, 1975, p. 1109). ¿A qué ripios se refiere Valéry? Aparte de la rima fácil entre "la multitud vil" y "la fiesta servil", probablemente también a la moral remanida: la muchedumbre que es azotada por el Placer, un verdugo demasiado alegórico, y corre a la fiesta a buscar algún remordimiento, mientras el que escribe, solo con su no menos alegórico Dolor, se aparta de todos. En cambio, los versos elogiados por Valéry hablaban de la tarde que da paso a la noche. El poeta le da la mano a su dolor en calma, que es una mujer, a la que invita a contemplar en la ciudad oscurecida cómo "se asoman los Años difuntos / en los balcones del cielo, con vestidos pasados de moda" y cómo sale "del fondo del agua la Nostalgia sonriente" y cómo "el Sol que agoniza se duerme bajo un arco" (1975, p. 141). Y a ese Dolor, femenino en francés, le dice al final: "Escucha, querida mía, escucha el paso suave de la Noche". ¿Cómo puede escucharse lo que se entrevé en el ocultamiento mismo de lo visible? ¿Qué es precisamente lo que el poeta se incita a escuchar en la noche? Es algo casi inaudible: "como una mortaja que se arrastra en el Oriente", el sonido que hace la capa negra de la noche al envolver un cuerpo cuyo dolor se ha unido con el tiempo de vida que lleva, el que le queda. El primer verso le decía también al Dolor en su persona: "quédate ya tranquila". La preocupación no apurará más los pasos de quien viste el luto completo, señal de ese duelo por aquello que no se recupera nunca, por los seres que no se recobran, por el yo que se pierde con la poesía del siglo. Queda la máscara del arte para el 
día, para el hipócrita lector de la mañana, y en su rictus o en su inteligencia, la indicación de una intensidad lejana, una invitación, una promesa de salvación, en la sonrisa de un pasado que vuelve.

Lo bello de Baudelaire, que es para nosotros un nombre rumiado íntimamente, lo "bello del aire", lo "bello del área", tiene dos partes: la apariencia, que es una forma de la ropa, que se muestra en la ciudad como luto; y el pensamiento, que se acumula en un interior, en el lugar del recogimiento, que es el sitio del duelo. Como se dijo al principio, estamos aludiendo a una sola palabra francesa, que significa a la vez los signos externos y el sentimiento del duelo, que en nuestro idioma no coinciden y quizás nunca coincidan. La joven de luto que pasa y no deja de mirar, un animal de feria que parece un emblema de la mitología y la literatura, lo que se pudre, lo que se ama, los ciudadanos rutinarios de traje, expresan en su tono luctuoso algo que Baudelaire llamaría "el alma pública". Pero en cada ocasión las palabras traen, fuera de lo visible, rítmicamente, el eco de una pérdida sin nombre: a la vez nostalgia y arrepentimiento. Y la única expectativa sería que al fin el poema exista y quizás le dé voz a lo que no se escucharía de otra forma. La forma de poema, como un luto antiguo, parece tan distante que no podría expresar la síncopa de un cuerpo que se pierde y que a veces es transportado por un pensamiento encabalgado en palabras. Pero cada uno que pasa, aunque se niegue a leer su propia negrura en las letras que sombrean la página, está reviviendo esa forma arcaica y de pronto, en la desesperación de aprovechar su día, ansía la llegada de la noche, "la dulce noche que camina"; sabe 
entonces, sin abrir la boca, que no está ahí para siempre. Esa lectura impensada puede ser, tal vez, una buena noticia, como dice Baudelaire en la prosa de "La pieza doble": "Sólo hay un Segundo en la vida humana que tiene la misión de anunciar una buena noticia, la buena noticia que a cada uno le causa un inexplicable miedo" (1975, p. 282). Da miedo el dolor, su cercanía, pero Baudelaire le dijo ya: "Sé sabio, Dolor mío"; sabía que la única escuela para escribir es el sufrimiento.

\section{Referencias Bibliográficas}

Baudelaire, C. (1868). Curiosités esthétiques. París: Michel Lévy Frères.

---. (1975). Oeuvres complètes. Claude Pichois (ed.). París: Gallimard, Bibliothèque de la Pléiade. 